\title{
The Importance of Contrast Volume/ Glomerular Filtration Rate Ratio in Contrast- Induced Nephropathy Patients after Transcatheter Aortic Valve Implantation
}

\author{
Ilker Gula Mustafa Zungur ${ }^{a} \quad$ Ahmet Tastan $^{a}$ Faik Fevzi Okur ${ }^{b}$ \\ Ertan Damar ${ }^{c}$ Samet Uyar ${ }^{a}$ Veysel Sahin ${ }^{b}$ Talat Tavli ${ }^{a}$ \\ Departments of a Cardiology, ${ }^{b}$ Cardiovascular Surgery and ${ }^{\mathrm{c} A n e s t h e s i o l o g y}$ and \\ Reanimation, Faculty of Medicine, Sifa University, Izmir, Turkey
}

\section{Key Words}

Severe aortic stenosis · Transcatheter aortic valve implantation · Contrast-induced nephropathy $\cdot$ Contrast volume $\cdot$ Glomerular filtration rate

\begin{abstract}
Background/Aim: Transcatheter aortic valve implantation (TAVI) is a method which is increasingly applied in severe aortic stenosis treatment. The development of contrast-induced nephropathy (CIN) after TAVI increases morbidity and mortality rates. Within the scope of this study, the importance of the contrast medium volume to glomerular filtration rate (CV/GFR) ratio in determining the development of CIN and the amount of CV that could be applied was evaluated. Methods: Seventy-two patients (aged $78.6 \pm 11.6$ years; 38 females) who underwent aortic valve replacement with the TAVI method between June 2013 and August 2014 were included in the study. CIN was defined as an absolute increase in serum creatinine of $>0.5 \mathrm{mg} / \mathrm{dl}$ or a relative increase of $>25 \%$ within $48-72 \mathrm{~h}$ after TAVI. CIN + and CIN- patients were classified into two groups. The $\chi^{2}$ test, $t$ test, Mann-Whitney $U$ test, ROC analysis, and univariate and multivariate regression analyses were applied for statistical analyses. Results: CIN was detected in 16 patients (22\%) in our study. Baseline creatinine, baseline GFR, the Mehran risk score, $C V$, and the CV/GFR ratio were determined as the predictive factors of CIN development. A CV/GFR ratio of 3.9 was specified to predict CIN development with $71 \%$ sensitivity and $80 \%$ specificity. Conclusion: After TAVI, CIN may develop due to various reasons. In patients to whom TAVI was applied, the CV/GFR ratio may be a guideline helping to prevent the development of renal pathologies. The amount of contrast medium that can be given to a patient can be calculated in terms of baseline GFR.




\section{CardioRenal Medicine}

\begin{tabular}{l|l}
\hline \multicolumn{2}{l|}{ Cardiorenal Med 2015;5:31-39 } \\
\hline DOI: 10.1159/000369943 & $\begin{array}{l}\text { ( ) 2014 S. Karger AG, Basel } \\
\text { www.karger.com/crm }\end{array}$ \\
\hline
\end{tabular}

Gul et al.: The Importance of Contrast Volume/Glomerular Filtration Rate Ratio in Contrast-Induced Nephropathy Patients after Transcatheter Aortic Valve Implantation

\section{Introduction}

If severe aortic stenosis (AS) is not treated, it develops into heart valve pathology with a high rate of morbidity and mortality [1]. Surgical methods or transcatheter procedures can be implemented for AS treatment. Aortic valve replacement with the transcatheter aortic valve implantation (TAVI) method can be performed in patients considered to be at high surgical risk or inoperable by the heart team [2]. As a result of clinical studies, it was determined that the TAVI method more effectively reduces morbidity and mortality rates compared to medical therapy [3]. In studies comparing TAVI and surgical aortic valve replacement, similar rates of efficiency were determined initially [4]. However, recent studies have suggested that TAVI is the more reliable method for high-risk or inoperable patients [5].

Contrast media are used for illustration purposes during TAVI. Renal function, which has been stable before TAVI, can be disrupted after the operation. According to the Valve Academic Research Consortium criteria, acute kidney injury (AKI) was defined as a change in serum creatinine up to $72 \mathrm{~h}$ compared with baseline, categorized as follows: stage 1, a 1.5- to 2-fold increase in creatinine or an absolute increase in the highest value of creatinine; stage 2, a 2.0to 3.0-fold increase in creatinine, and stage 3, a $\geq 3.0$-fold increase in creatinine [6]. In the case of AKI after invasive interventional operations, morbidity and mortality increase [7-9]. Contrast-induced nephropathy (CIN) is one of the reasons for AKI development in the hospital [10]. CIN was defined as an absolute increase in serum creatinine of $>0.5 \mathrm{mg} / \mathrm{dl}$ or a relative increase of $>25 \%$ within $48-72 \mathrm{~h}$ after TAVI [11]. Thus, factors that can lead to the development of CIN after interventional cardiovascular operations must be well known. It has been specified that the contrast medium volume (CV) used in invasive operations is the most important factor causing AKI $[12,13]$. The CV/glomerular filtration rate (GFR) ratio, a useful indicator of the development of nephropathy, depends on the amount of contrast medium administered after percutaneous coronary intervention (PCI) [14]. CIN appearing in elderly and high-risk TAVI patients can influence the overall condition of the patients. Up to date, several studies have been conducted related to factors affecting the development of CIN in patients with TAVI. However, the importance of the CV/GFR ratio in predicting the development of CIN has not yet been investigated in detail. The importance of the CV/GFR ratio in the prediction of CIN development and in determining the amount of contrast medium that can be applied safely to TAVI patients was evaluated in this study.

\section{Methods}

\section{Study Population and Data Collection}

For this study, 72 patients who underwent aortic valve replacement with the TAVI method at our center were evaluated between June 2013 and August 2014. Patients who were considered appropriate for the TAVI method by our heart team were included in the study because they were inoperable or at high risk for surgical aortic valve replacement. The operative risks of patients were calculated with the logistic European System for Cardiac Operative Risk Evaluation (Logistic EuroSCORE) and the Society of Thoracic Surgeons Predictive Risk of Mortality (STS) scores. Patients with a logistic EuroSCORE $>20 \%$ or a STS score $>10 \%$ were considered high-risk patients [15]. These cases underwent dialysis before TAVI, and those with a creatinine value $>2.5$ $\mathrm{mg} / \mathrm{dl}$ and with permanent pacemakers were not included in the study. Clinical data, patient characteristics, echocardiographic data, processual variables, morbidity and mortality rates were prospectively followed up for 6 months. Controls at the second week, first, third, and sixth month after patient discharge were performed at our center.

Study Protocol

Severe AS was diagnosed with echocardiographic methods. An average aortic gradient $>40 \mathrm{~mm} \mathrm{Hg}$, an aortic valve area $<1 \mathrm{~cm}^{2}$, and a valve area index (valve area/body surface area) $<0.6 \mathrm{~cm}^{2}$ were considered to 


\section{CardioRenal Medicine}

\begin{tabular}{l|l}
\hline Cardiorenal Med 2015;5:31-39 \\
\hline DOI: 10.1159/000369943 & $\begin{array}{l}\text { @ 2014 S. Karger AG, Basel } \\
\text { www.karger.com/crm }\end{array}$ \\
\hline
\end{tabular}

Gul et al.: The Importance of Contrast Volume/Glomerular Filtration Rate Ratio in Contrast-Induced Nephropathy Patients after Transcatheter Aortic Valve Implantation

indicate severe AS [15]. A balloon-expandable Edwards Sapien XT valve (Edwards Lifesciences, Irvine, Calif., USA) was used for the TAVI process. A vascular occlusion device (ProStar XL; Abbott Laboratories, North Chicago, Ill., USA) was used in eligible patients for femoral artery diameter and anatomical measurements. The surgical cutdown method was applied to patients who were unsuitable for the iliac and femoral artery anatomy vascular closure device. Transesophageal echocardiography and multislice CT tests were done to determine the diameter of the implanted aortic bioprosthesis. In all patients, clopidogrel $75 \mathrm{mg}$, acetylsalicylic acid $100 \mathrm{mg}$, and intravenous antibiotherapy was started before the operation. Iohexol (Omnipaque; GE Healthcare), a nonionic, low-osmolar, and monomeric contrast medium, was used as opaque material. The amount of contrast medium used was recorded during TAVI. Examinations such as CT and coronary angiography that required the administration of contrast medium except for the TAVI procedures were performed at least $72 \mathrm{~h}$ previously. The daily renal functions of all patients were monitored from admission to discharge. Creatinine levels were checked in the second week, the first, third, and sixth month after the operation (COBAS Integra 400 plus; Roche Diagnostics).

Estimated GFR was calculated with the Modification of Diet in Renal Disease formula: GFR (expressed in $\left.\mathrm{ml} / \mathrm{min} / 1.73 \mathrm{~m}^{2}\right)=186 \times \mathrm{SCr}^{1.154} \times$ age $^{0.203}(\times 0.742$ female gender $)$. Before TAVI, $1 \mathrm{ml} / \mathrm{kg} / \mathrm{h}$ of $0.9 \% \mathrm{NaCl}$ solution was administered for $24 \mathrm{~h}$ to the patients with a GFR $<50 \mathrm{ml} / \mathrm{min} / 1.73 \mathrm{~m}^{2} ; 48-72 \mathrm{~h}$ after the TAVI operation, $0.5 \mathrm{mg} / \mathrm{dl}$ or a $25 \%$ increase compared to the basal creatinine value was defined as CIN [11, 15-20]. Our study was conducted in accordance with the Declaration of Helsinki, and the study protocol was approved by the local ethics committee.

\section{Statistical Analysis}

Analysis was performed with SPSS 17.0 software (SPSS, Chicago, Ill., USA). To test the distribution pattern, the Kolmogorov-Smirnov method was used. Continuous variables were expressed as the mean \pm SD, and the categorical variables were expressed as percentages. To identify the correlations between CIN and the clinical or laboratory parameters, a univariate analysis was performed using an unpaired $t$ test or MannWhitney $U$ test for the continuous variables and the $\chi^{2}$ test for the categorical variables, respectively. A multivariate logistic regression analysis was used to assess the correlation among the parameters, whose statistical significance was demonstrated on a univariate analysis level of $\mathrm{p}<0.05$ and through well-known risk factors. Models were developed with stepwise techniques, for which the results were expressed as odds ratios with 95\% confidence intervals (CIs). An exploratory evaluation for additional cut points of different variables was performed using the receiver operating characteristic (ROC) curve analysis. Significant difference was defined as $\mathrm{p}<0.05$.

\section{Results}

\section{General Characteristics of Patients}

Seventy-two patients (aged $78.6 \pm 11.6$ years; 38 females) were included in our study. No significant differences between the groups in terms of demographic, laboratory, and echocardiographic characteristics were found. The mean STS score in the CIN+ group was higher ( $p=0.028$ ) compared to that in the CIN- group. When the risk factors were evaluated, a difference between the groups in terms of coronary artery disease, diabetes mellitus, hypertension, chronic obstructive pulmonary disease, and peripheral arterial disease was not ascertained (tables 1,2).

\section{Procedure}

A balloon-expandable Edwards Sapien XT valve via transfemoral access was implanted in all patients. The average radiation time was $8.2 \pm 3.1 \mathrm{~min}$. The average $\mathrm{CV}$ and the average extubation times were $191.4 \pm 33.2$ and $204 \pm 43.1 \mathrm{~min}$, respectively. The length of stay in the intensive care unit and the length of stay at the hospital were $1.47 \pm 0.9$ and $4.44 \pm 3.1$ days, respectively.

CIN after TAVI was observed in a total of 16 patients (22.2\%). The CIN group's length of stay in the intensive care unit and the length of stay at the hospital were $1.6 \pm 1.4$ and 
Table 1. Demographic and operation characteristics of the patients

\begin{tabular}{|c|c|c|c|}
\hline Variables & $\mathrm{CIN}+(\mathrm{n}=16)$ & CIN- $(n=56)$ & $\mathrm{p}$ value \\
\hline Age, years & $78.6 \pm 6.1$ & $76.3 \pm 7.9$ & 0.218 \\
\hline Females & $11(68.8)$ & $27(48.2)$ & 0.121 \\
\hline Body mass index & $29.2 \pm 9.4$ & $27.7 \pm 4.1$ & 0.091 \\
\hline Previous cardiac operation $(n=12,16.7 \%)$ & $1(6.3)$ & $11(19.6)$ & 0.191 \\
\hline Previous PCI $(n=19,26.4 \%)$ & $2(12.5)$ & 17 (30.4) & 0.132 \\
\hline Coronary artery disease $(n=44,61.1 \%)$ & $10(62.5)$ & $34(60.7)$ & 0.569 \\
\hline Permanent pacemaker & 0 & 0 & n.s. \\
\hline Diabetes mellitus $(n=30,41.7 \%)$ & $9(56.3)$ & $21(37.5)$ & 0.146 \\
\hline Arterial hypertension $(n=48,66.7 \%)$ & $12(75.0)$ & $36(64.3)$ & 0.314 \\
\hline Chronic obstructive pulmonary disease $(n=46,63.9 \%)$ & $10(62.5)$ & $36(64.3)$ & 0.559 \\
\hline GFR, $\mathrm{ml} / \mathrm{min} / 1.73 \mathrm{~m}^{2}$ & $54.3 \pm 17.9$ & $62.7 \pm 21.8$ & 0.162 \\
\hline Logistic EuroSCORE, \% & $37.1 \pm 10.9$ & $36.4 \pm 15.5$ & 0.303 \\
\hline STS score, $\%$ & $16.5 \pm 9.7$ & $12.8 \pm 4.1$ & 0.028 \\
\hline $\mathrm{CV}, \mathrm{ml}$ & $203.4 \pm 41.3$ & $170.2 \pm 30.9$ & $<0.001$ \\
\hline CV/GFR ratio & $4.6 \pm 1.5$ & $3.7 \pm 1.7$ & 0.001 \\
\hline Intensive care unit stay, days & $1.6 \pm 1.1$ & $1.4 \pm 0.9$ & 0.679 \\
\hline Total hospital stay, days & $4.8 \pm 1.6$ & $4.3 \pm 1.4$ & 0.250 \\
\hline Mortality, in hospital (n = 2, 2.8\%) & $1(6.3)$ & $1(1.8)$ & 0.925 \\
\hline Mortality, $1-6$ months $(n=3,4.1 \%)$ & $2(12.5)$ & $1(1.8)$ & 0.108 \\
\hline Total mortality $(n=5,6.9 \%)$ & $3(18.8)$ & $2(2.8)$ & 0.038 \\
\hline Stroke & 0 & 0 & n.s. \\
\hline Major bleeding $(n=6,8.3 \%)$ & $2(12.5)$ & $4(7.1)$ & 0.401 \\
\hline Minor bleeding $(n=15,20.8 \%)$ & $3(18.8)$ & $12(21.4)$ & 0.561 \\
\hline
\end{tabular}

Data are presented as mean \pm SD or number (\%). n.s. = Not significant.

Table 2. Laboratory data and echocardiographic findings

\begin{tabular}{lccc}
\hline Variables & CIN+ & CIN- & p value \\
\hline Baseline creatinine, mg/dl & $1.20 \pm 0.64$ & $1.11 \pm 0.29$ & 0.689 \\
Urea, mg/dl & $51.4 \pm 22.9$ & $48.2 \pm 18.2$ & 0.666 \\
Potassium, mmol/l & $5.12 \pm 1.41$ & $4.51 \pm 0.53$ & 0.716 \\
Brain natriuretic peptide, pg/ml & $7,880.6 \pm 4,687.4$ & $7,044.8 \pm 3,968.5$ & 0.125 \\
High-sensitive troponin T & $22.8 \pm 17.5$ & $20.3 \pm 18.9$ & 0.920 \\
Low-density lipoprotein, mg/dl & $128.9 \pm 45.7$ & $109.0 \pm 34.5$ & 0.126 \\
Hemoglobin, g/dl & $11.2 \pm 1.85$ & $11.4 \pm 1.85$ & 0.832 \\
Platelets, $\times 10^{3} / \mu l$ & $255.2 \pm 73.7$ & $261.9 \pm 125.5$ & 0.129 \\
White blood cells, $\times 10^{3} / \mu \mathrm{l}$ & $13.6 \pm 8.7$ & $7.6 \pm 2.8$ & 0.257 \\
C-reactive protein, $\mathrm{mg} / \mathrm{l}$ & $4.0 \pm 3.0$ & $2.9 \pm 2.6$ & 0.657 \\
Left ventricular ejection fraction, \% & $41.5 \pm 11.1$ & $44.3 \pm 9.3$ & 0.263 \\
Aortic valve area (before TAVI), cm ${ }^{2}$ & $0.63 \pm 0.08$ & $0.62 \pm 0.09$ & 0.968 \\
Aortic valve area (6 months after TAVI), cm ${ }^{2}$ & $1.75 \pm 0.24$ & $1.81 \pm 0.42$ & 0.762 \\
Mean aortic gradient (before TAVI), mm Hg & $49.9 \pm 9.4$ & $51.4 \pm 11.3$ & 0.604 \\
Mean aortic gradient (6 months after TAVI), mm Hg & $8.4 \pm 2.4$ & $7.9 \pm 1.8$ & 0.425 \\
Postaortic regurgitation grade $\geq 2$ & $1(6.3)$ & $4(7.1)$ & 0.987 \\
sPAP (before TAVI), mm Hg & $48.5 \pm 10.8$ & $43.9 \pm 7.6$ & 0.179 \\
\hline
\end{tabular}

Data are presented as mean \pm SD or number $(\%)$. sPAP $=$ Systolic pulmonary artery pressure. 
Gul et al.: The Importance of Contrast Volume/Glomerular Filtration Rate Ratio in

Table 3. Univariate and multivariate analysis of risk factors determining CIN

\begin{tabular}{|c|c|c|c|c|}
\hline \multirow[t]{2}{*}{ Variables } & \multicolumn{2}{|c|}{ Univariate analysis } & \multicolumn{2}{|c|}{ Multivariate analysis } \\
\hline & odds ratio & $\mathrm{p}$ value & odds ratio & $\mathrm{p}$ value \\
\hline Age & $1.1(0.8-1.4)$ & 0.057 & - & - \\
\hline Diabetes mellitus & $1.6(0.8-2.6)$ & 0.092 & - & - \\
\hline Coronary artery disease & $1.8(0.8-3.5)$ & 0.062 & - & - \\
\hline STS score & $1.2(0.9-1.4)$ & 0.017 & $1.2(0.9-1.5)$ & 0.079 \\
\hline Logistic EuroSCORE & $1.1(0.9-1.3)$ & 0.087 & - & - \\
\hline Ejection fraction & $1.0(0.8-1.3)$ & 0.154 & - & - \\
\hline Creatinine & $2.0(1.1-3.1)$ & 0.011 & $1.9(1.2-2.7)$ & 0.032 \\
\hline GFR & $3.1(1.4-7.2)$ & $<0.001$ & $2.3(1.2-4.2)$ & 0.005 \\
\hline $\mathrm{CV}$ & $8.9(4.7-15.3)$ & $<0.001$ & $3.9(1.7-8.5)$ & $<0.001$ \\
\hline CV/GFR ratio & $10.9(4.9-23.1)$ & $<0.001$ & $4.9(1.9-12.2)$ & $<0.001$ \\
\hline Mehran score & $2.5(1.5-3.1)$ & $<0.001$ & $2.0(1.2-3.0)$ & 0.024 \\
\hline Hemoglobin & $0.9(0.7-1.1)$ & 0.108 & - & - \\
\hline
\end{tabular}

Figures in parentheses are 95\% CIs.

$4.8 \pm 1.6$ days, respectively. After TAVI, none of the patients needed permanent pacemaker implantation due to atrioventricular conduction block. Vascular injuries occurred in 12 patients; 4 of these patients were in the CIN+ group $(\mathrm{p}=0.254)$. Urgent surgical intervention was required for 4 patients with vascular complications (5.6\%). Three of them were in the CIN+ group (5.4\%). A differentiation between the groups in terms of stroke and bleeding complications was not ascertained. The amount of applied CV was higher in the CIN+ group $(\mathrm{p}<0.001)$. Five patients died during the study period, and 2 of them passed away in the first month $(1 \mathrm{CIN}+$ patient and $1 \mathrm{CIN}-$ patient; $\mathrm{p}=0.925)$. Between the first and the sixth month of follow-up, another 3 patients passed away ( $2 \mathrm{CIN}+$ patients and $1 \mathrm{CIN}-$ patient; $p=0.108$ ). It has been ascertained that the total mortality in the CIN+ group was higher compared to that in the CIN- group (18.8 vs. $2.8 \%$; $p=0.038$ ) (table 1 ).

\section{CIN Predictors}

In univariate analysis, which was conducted to determine CIN predictors after TAVI, it had been ascertained that statistically significant $\mathrm{p}$ values of the STS score, basal keratin, basal GFR, CV, Mehran score, and CV/GFR ratio were $<0.05$. Multivariate regression analysis was performed with these variables. We have detected that other variables apart from the STS score can predict the development of CIN (table 3). A ROC analysis of the variables determined as significant with multivariate regression analysis was performed. As a result of this ROC analysis, the CV/GFR ratio which may predict the development of CIN was determined as 3.9 [area under the curve (AUC) $0.773,95 \%$ CI $0.604-0.906$, sensitivity $71 \%$, specificity 80\%] (fig. 1, 2; table 4).

\section{Discussion}

According to the results of our study, the CV/GFR ratio can be used to predict the development of CIN in patients undergoing TAVI. It has been shown that a CV/GFR ratio $>3.9$ is a critical limit in predicting the development of CIN.

After invasive cardiovascular procedures, the mechanisms of kidney damage caused by contrast medium are not exactly clarified. It has been thought that toxicity resulting from the 
CardioRenal

Medicine

Fig. 1. ROC curve for the predictors of CIN using baseline creatinine, CV, baseline GFR, Mehran score, and CV/GFR ratio.

Fig. 2. ROC curve for the predictors of CIN using GFR. The AUC for predicting CIN using GFR was 0.625 (sensitivity $57 \%$, specificity 75\%, 95\% CI 0.477-0.773, cutoff $50.5 \mathrm{ml} / \mathrm{min} / 1.73 \mathrm{~m}^{2}$ ).
Gul et al.: The Importance of Contrast Volume/Glomerular Filtration Rate Ratio in Contrast-Induced Nephropathy Patients after Transcatheter Aortic Valve Implantation
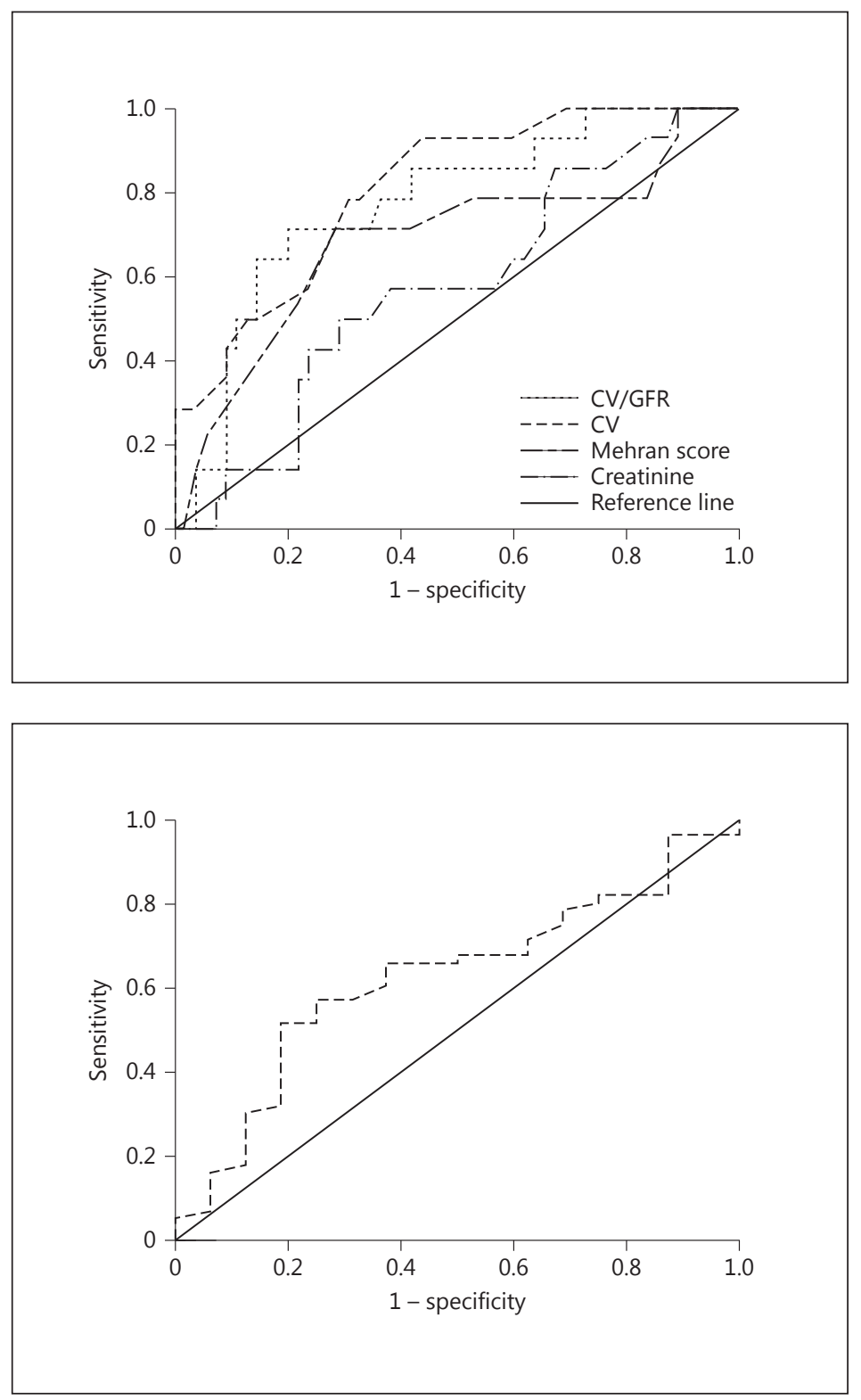

Table 4. ROC results for the prediction of CIN using baseline creatinine, baseline GFR, Mehran score, CV, and $\mathrm{CV} / \mathrm{GFR}$ ratio

\begin{tabular}{lrllll}
\hline & Cutoff & AUC & Sensitivity, \% & Specificity, \% & $95 \%$ CI \\
\hline CV/GFR ratio & 3.91 & 0.773 & 71 & 80 & $0.640-0.906$ \\
CV & 197.5 & 0.808 & 79 & 69 & $0.692-0.925$ \\
Mehran score & 16.5 & 0.684 & 50 & 80 & $0.509-0.859$ \\
Basal GFR & 50.5 & 0.625 & 57 & 75 & $0.477-0.773$ \\
Basal creatinine & 1.17 & 0.577 & 50 & 71 & $0.416-0.737$ \\
\hline
\end{tabular}


characteristics of the contrast medium and the resultant degree of renal ischemia played a role in the development of CIN. On the other hand, there are many factors which can facilitate CIN development. These can be divided into two groups depending on patient characteristics and invasive surgery. The prominent facilitating characteristics of patients are: age, diabetes mellitus, cardiac insufficiency, and impaired basic renal functions [21, 22]. However, these variables do not differ among the groups in our study (tables 1,2). With regard to surgery, factors that facilitate CIN development are: increase in the amount of contrast medium, hemodynamic irregularities, and hypotension [12-21]. During TAVI operation in particular, hypotensive periods may occur, thus increasing CIN probability.

According to Nash et al. [10], CIN is one of the most significant causes of hospital-acquired renal insufficiency. CIN ratios after TAVI are reported to be 10-30\% [23-25]. In our study, CIN was detected in 16 patients (22.2\%), which is similar to those ratios mentioned above. A significant increase in morbidity has been reported in earlier studies when cardiovascular pathology coexists with renal dysfunction. Similarly, the development of renal insufficiencies after aortic valve implementations increases mortality $[10,26]$. However, in our study, in the first 6 months of follow-up, no statistically significant difference was observed in terms of morbidities. When complications were evaluated separately, the rates in the CIN+ group were higher but statistically not significant. This situation was attributed to the low number of patients. Bagur et al. [27] reported that mortality was 7\% in aortic valve implementation without kidney injury, whereas with kidney injury, the rate was $15 \%$. In our study, mortality rates during the 6 months of follow-up are remarkably higher for those who presented CIN (18.8 vs. $2.8 \% ; p=0.038$ ). Even if the deterioration in basal kidney functions which might lead to CIN development cannot be totally cured, it is a risk factor which can be modified by the amount of CV used. So far, many studies have been conducted on renal functions of patients who have undergone TAVI, but the ratio of CV to creatinine clearance (CV/CCR) which can provide a prediction of CIN development has been determined earlier. Worasuwannarak et al. [28] noted that a CV/CCR $>2.6$ after PCI could predict CIN development. Yamamato et al. [16] showed that in TAVI patients, a CV/CCR $>3.7$ is related with AKI. However, for increased levels of serum creatinine, GFR must be approximately $50 \%$ decreased. Thus, by the Cockcroft-Gault formula, creatinine clearance might be calculated higher than it should be. The accuracy of GFR calculation is higher for impaired or normal kidneys. For the evaluation of CIN development, the CV/GFR ratio can be assumed as a more reliable parameter than the CV/CCR. Nozue et al. [29] remarked that the CV/GFR ratio is one of the predictors of CIN development in patients who receive elective PCI. Wang et al. [14] have found the CV/GFR ratio which could predict CIN development after PCI to be 3.1 (AUC 0.736, 95\% CI 0.631 $0.841, \mathrm{p}=0.001$, sensitivity $71 \%$, specificity $70 \%$ ) in diabetic patients with ST elevation myocardial infarction. According to the results of our study, CV, baseline creatinine, Mehran score, baseline GFR, and CV/GFR are fundamental variables which may lead to CIN after TAVI. According to the results of the statistical analyses, it is ascertained that the most important variables which directly affect CIN development after TAVI are CV and CV/GFR. According to ROC analysis, the CV/GFR ratio predicting CIN development is 3.9 (AUC 0.773 , 95\% CI 0.6040.906 , sensitivity $71 \%$, specificity $80 \%$ ).

\section{Limitations}

The basic limitations to our study are the low number of patients and that it was managed from a single center. Therefore, although the number of patients in the CIN+ group which experiences complications is huge, it may not have statistical significance. The main reasons (radiotoxic, nephrotoxic, ischemic) of CIN development were not put forth in depth because renal biopsy was not carried out. We feel that as the duration of follow-up rises, statistical differences will become clear. 


\section{Conclusion}

In conclusion, it was determined that even if morbidity and mortality rates are low, the CV/GFR ratio - as in PCI procedures - is one of the predictors of CIN development also in TAVI. However, it is not a set rule. Regarding the basal GFR of the patients, the maximum amount of contrast medium to be used can be calculated in advance. We determine that before TAVI, the $\mathrm{CV}$ amount to be given should be calculated to provide a CV/GFR ratio $<3.9$ in order that renal complications might possibly be reduced.

\section{Disclosure Statement}

The authors declare no conflicts of interest.

\section{References}

$>1$ Turina J, Hess O, Sepulcri F, Krayenbuehl HP: Spontaneous course of aortic valve disease. Eur Heart J 1987;8: 471-483.

-2 Cribier A: Development of transcatheter aortic valve implantation (TAVI): a 20-year odyssey. Arch Cardiovasc Dis 2012;105:146-152.

-3 Figulla L, Neumann A, Figulla HR, Kahlert P, Erbel R, Neumann T: Transcatheter aortic valve implantation: evidence on safety and efficacy compared with medical therapy. A systematic review of current literature. Clin Res Cardiol 2011;100:265-276.

4 Leon MB, Smith CR, Mack M, Miller DC, Moses JW, Svensson LG, Tuzcu EM, Webb JG, Fontana GP, Makkar RR, Brown DL, Block PC, Guyton RA, Pichard AD, Bavaria JE, Herrmann HC, Douglas PS, Petersen JL, Akin JJ, Anderson WN, Wang D, Pocock S; PARTNER Trial Investigators: Transcatheter aortic-valve implantation for aortic stenosis in patients who cannot undergo surgery. N Engl J Med 2010;363:1597-1607.

-5 Adams DH, Popma JJ, Reardon MJ, Yakubov SJ, Coselli JS, Deeb GM, Gleason TG, Buchbinder M, Hermiller J Jr, Kleiman NS, Chetcuti S, Heiser J, Merhi W, Zorn G, Tadros P, Robinson N, Petrossian G, Hughes GC, Harrison JK, Conte J, Maini B, Mumtaz M, Chenoweth S, Oh JK; CoreValve US Clinical Investigators: Transcatheter aorticvalve replacement with a self-expanding prosthesis. N Engl J Med 2014;370:1790-1798.

6 Leon MB, Piazza N, Nikolsky E, Blackstone EH, Cutlip DE, Kappetein AP, Krucoff MW, Mack M, Mehran R, Miller C, Morel MA, Petersen J, Popma JJ, Takkenberg JJ, Vahanian A, van Es GA, Vranckx P, Webb JG, Windecker S, Serruys PW: Standardized endpoint definitions for transcatheter aortic valve implantation clinical trials: a consensus report from the Valve Academic Research Consortium. Eur Heart J 2011;32:205-217.

7 Rihal CS, Textor SC, Grill DE, Berger PB, Ting HH, Best PJ, Singh M, Bell MR, Barsness GW, Mathew V, Garratt $\mathrm{KN}$, Holmes DR Jr: Incidence and prognostic importance of acute renal failure after percutaneous coronary intervention. Circulation 2002;105:2259-2264.

-8 Aregger F, Wenaweser P, Hellige GJ, Kadner A, Carrel T, Windecker S, Frey FJ: Risk of acute kidney injury in patients with severe aortic valve stenosis undergoing transcatheter valve replacement. Nephrol Dial Transplant 2009;24:2175-2179.

-9 Nuis RJ, Van Mieghem NM, Tzikas A, Piazza N, Otten AM, Cheng J, van Domburg RT, Betjes M, Serruys PW, de Jaegere PP: Frequency, determinants and prognostic effects of acute kidney injury and red blood cell transfusion in patients undergoing transcatheter aortic valve implantation. Catheter Cardiovasc Interv 2011;77: 881-889.

10 Nash K, Hafeez A, Hou S: Hospital-acquired renal insufficiency. Am J Kidney Dis 2002;39:930-936.

11 Mehran R, Nikolsky E: Contrast-induced nephropathy: definition, epidemiology, and patients at risk. Kidney Int Suppl 2006;100:11-15.

12 Dangas G, Iakovou I, Nikolsky E, Aymong ED, Mintz GS, Kipshidze NN, Lansky AJ, Moussa I, Stone GW, Moses JW, Leon MB, Mehran R: Contrast-induced nephropathy after percutaneous coronary interventions in relation to chronic kidney disease and hemodynamic variables. Am J Cardiol 2005;95:13-19.

-13 Yamamoto M, Hayashida K, Mouillet G, Chevalier B, Meguro K, Watanabe Y, Dubois-Rande JL, Morice MC, Lefèvre T, Teiger E: Renal function-based contrast dosing predicts acute kidney injury following transcatheter aortic valve implantation. J Am Coll Cardiol Cardiovasc Interv 2013;6:479-486.

14 Wang XC, Fu XH, Wang YB, Jia XW, Wu WL, Gu XS, Zhang J, Su JL, Hao GZ, Jiang YF, Fan WZ, Li SQ: Prediction of contrast-induced nephropathy in diabetics undergoing elective percutaneous coronary intervention: role of the ratio of contrast medium volume to estimated glomerular filtration rate. Chin Med J 2011;124:892-896. 


\section{CardioRenal Medicine}

15 Vahanian A, Alfieri O, Andreotti F, Antunes MJ, Barón-Esquivias G, Baumgartner H, Borger MA, Carrel TP, De Bonis M, Evangelista A, Falk V, Lung B, Lancellotti P, Pierard L, Price S, Schäfers HJ, Schuler G, Stepinska J, Swedberg K, Takkenberg J, Von Oppell UO, Windecker S, Zamorano JL, Zembala M; ESC Committee for Practice Guidelines (CPG); Joint Task Force on the Management of Valvular Heart Disease of the European Society of Cardiology (ESC); European Association for Cardio-Thoracic Surgery (EACTS): Guidelines on the management of valvular heart disease (version 2012): the Joint Task Force on the Management of Valvular Heart Disease of the European Society of Cardiology (ESC) and the European Association for Cardio-Thoracic Surgery (EACTS). Eur J Cardiothorac Surg 2012;42:1-44.

16 Yamamoto M, Meguro K, Mouillet G, Bergoend E, Monin JL, Lim P, Dubois-Rande JL, Teiger E: Comparison of effectiveness and safety of transcatheter aortic valve implantation in patients aged $\geq 90$ years versus $<90$ years. Am J Cardiol 2012;110:1156-1163.

-17 Hayashida K, Lefèvre T, Chevalier B, Hovasse T, Romano M, Garot P, Mylotte D, Uribe J, Farge A, Donzeau-Gouge P, Bouvier E, Cormier B, Morice MC: True percutaneous approach for transfemoral aortic valve implantation using the Prostar XL device: impact of learning curve on vascular complications. J Am Coll Cardiol Cardiovasc Interv 2012;5:207-214.

18 Hayashida K, Bouvier E, Lefèvre T, Hovasse T, Morice MC, Chevalier B, Romano M, Garot P, Mylotte D, Farge A, Donzeau-Gouge P, Cormier B: Impact of CT-guided valve sizing on post-procedural aortic regurgitation in transcatheter aortic valve implantation. EuroIntervention 2012;8:546-555.

19 Levey AS, Bosch JP, Lewis JB, Greene T, Rogers N, Roth D: A more accurate method to estimate glomerular filtration rate from serum creatinine: a new prediction equation. Modification of Diet in Renal Disease Study Group. Ann Intern Med 1999;130:461-470.

-20 Mueller C, Buerkle G, Buettner HJ, Petersen J, Perruchoud AP, Eriksson U, Marsch S, Roskamm H: Prevention of contrast media-associated nephropathy: randomized comparison of 2 hydration regimens in 1,620 patients undergoing coronary angioplasty. Arch Intern Med 2002;162:329-336.

-21 Mehran R, Aymong ED, Nikolsky E, Lasic Z, Iakovou I, Fahy M, Mintz GS, Lansky AJ, Moses JW, Stone GW, Leon MB, Dangas G: A simple risk score for prediction of contrast-induced nephropathy after percutaneous coronary intervention: development and initial validation. J Am Coll Cardiol 2004;44:1393-1399.

22 Goldenberg I, Matetzky S: Nephropathy induced by contrast media: pathogenesis, risk factors and preventive strategies. Can Med Assoc J 2005;172:1461-1471.

23 Chertow GM, Levy EM, Hammermeister KE, Grover F, Daley J: Independent association between acute renal failure and mortality following cardiac surgery. Am J Med 1998;104:343-348.

-24 Karkouti K, Wijeysundera DN, Yau TM, Callum JL, Cheng DC, Crowther M, Dupuis JY, Fremes SE, Kent B, Laflamme C, Lamy A, Legare JF, Mazer CD, McCluskey SA, Rubens FD, Sawchuk C, Beattie WS: Acute kidney injury after cardiac surgery: focus on modifiable risk factors. Circulation 2009;119:495-502.

-25 Lok CE, Austin PC, Wang H, Tu JV: Impact of renal insufficiency on short- and long-term outcomes after cardiac surgery. Am Heart J 2004;148:430-438.

-26 Elhmidi Y, Bleiziffer S, Piazza N, Hutter A, Opitz A, Hettich I, Kornek M, Ruge H, Brockmann G, Mazzitelli D, Lange R: Incidence and predictors of acute kidney injury in patients undergoing transcatheter aortic valve implantation. Am Heart J 2011;161:735-739.

-27 Bagur R, Webb JG, Nietlispach F, Dumont E, De Larochellière R, Doyle D, Masson JB, Gutiérrez MJ, Clavel MA, Bertrand OF, Pibarot P, Rodés-Cabau J: Acute kidney injury following transcatheter aortic valve implantation: predictive factors, prognostic value, and comparison with surgical aortic valve replacement. Eur Heart J 2010; 31:865-874.

28 Worasuwannarak S, Pornratanarangsi S: Prediction of contrast-induced nephropathy in diabetic patients undergoing elective cardiac catheterization or PCI: role of volume-to-creatinine clearance ratio and iodine dose-to-creatinine clearance ratio. J Med Assoc Thai 2010;93:29-34.

29 Nozue T, Michishita I, Iwaki T, Mizuguchi I, Miura M: Contrast medium volume to estimated glomerular filtration rate ratio as a predictor of contrast-induced nephropathy developing after elective percutaneous coronary intervention. J Cardiol 2009;54:214-220. 